VIEIRA, J.N., et al. Bubalinocultura no Brasil: Short communication. PUBVET, Londrina, V. 5, N. 2, Ed. 149, Art. 1003, 2011.

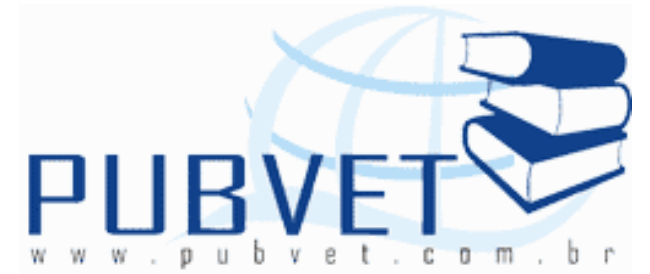

PUBVET, Publicações em Medicina Veterinária e Zootecnia.

\title{
Bubalinocultura no Brasil - Short comunication
}

Juliana Nobre Vieira ${ }^{1}$, Cláudia Salviano Teixeira*², Marcelo Yukio Kuabara*3; Denise Aparecida Andrade de Oliveira ${ }^{2,4}$

${ }^{1}$ Doutoranda, Departamento de Zootecnia, Escola de Veterinária da UFMG, Belo Horizonte, MG, Brasil; Bolsista FAPEMIG - TCT n012.020/2009

${ }^{2}$ Escola de Veterinária da UFMG, Belo Horizonte, Belo Horizonte, MG, Brasil $*^{3}$ Co-orientadores

${ }^{4}$ Professora Associada EV-UFMG - Orientadora

${ }^{1}$ Correspondência: nobrevieira.j@gmail.com

\section{Resumo}

A bubalinocultura é caracterizada pela criação de búfalos domésticos asiáticos que são altamente adaptados à inserção na cadeia agroindustrial de carne e leite. Esses animais possuem ótima adaptação ao Brasil e uma promissora habilidade em produção. O efetivo de bubalinos em 31.12.2007 (IBGE) foi de 1.131 .986 cabeças, o maior efetivo desta espécie encontra-se localizado do Norte do País (704.424 cabeças, 62,3\%), seguido das regiões Sul (127.966, $11,3 \%)$, Nordeste $(119.978,10,6 \%)$, Sudeste $(110.769,9,8 \%)$ e Centro-Oeste $(68.849,6 \%)$. Estes dados demonstram que a bubalinocultura é uma atividade econômica relevante no Brasil e que os produtos derivados de búfalos estão sendo cada vez mais comercializados. Desta forma, faz-se necessário adequar o sistema de produção, como, por exemplo, a identificação genética, 
VIEIRA, J.N., et al. Bubalinocultura no Brasil: Short communication. PUBVET, Londrina, V. 5, N. 2, Ed. 149, Art. 1003, 2011.

melhoramento genético, registro de doenças genéticas e estudo de doenças patológicas, seleção para fertilidade e controle qualidade de carne, leite e derivados. Determinando, assim, um registro apropriado do rebanho nacional, uma vez que o Brasil detém o maior rebanho da espécie do Ocidente.

Palavras-chave: búfalo, agronegócio

\section{Buffalo agribusiness in Brazil - Short comunication}

\section{Abstract}

Agribusiness buffalo is characterized by the creation of Asian domestic buffalo are highly adapted for inclusion in agribusiness supply chain of meat and milk. These animals have great adapted to Brazil and a promising ability in production. The effective buffaloes 2007.12.31 (IBGE) was 1.131 .986 head, the biggest number of these species is located in the North Country (704.424 head, $62.3 \%)$, followed by the South $(127.966,11.3 \%)$, Northeast $(119.978$, $10.6 \%)$, Southeast $(110.769,9.8 \%)$ and Center-West $(68.849,6 \%)$. These data demonstrate that buffalo creation is an important economic activity in Brazil and their products are increasingly marketed. Thus, it is necessary to adapt the production system, for example, genetic identification, breeding, registration of genetic diseases and study of diseases pathological studies, selection for fertility and control quality of meat, milk and derivatives. Determining an appropriate register of the national breed, a time that Brazil has the largest breed of the species of the West.

Keywords: buffalo, agribusiness

\section{INTRODUÇÃO}

A criação de búfalos vem crescendo em todo o mundo. A participação da espécie bubalina na produção de alimento nas áreas tropicais e subtropicais aumenta consideravelmente. A criação de búfalos destaca-se por ser uma atividade capaz de incluir pequenos produtores no cenário produtivo, já que 
VIEIRA, J.N., et al. Bubalinocultura no Brasil: Short communication. PUBVET, Londrina, V. 5, N. 2, Ed. 149, Art. 1003, 2011.

estes animais apresentam capacidade de sobreviver em locais inóspitos aos bovinos, docilidade, alto valos agregado em seus produtos derivados e maior rendimento industrial do leite de búfalos em relação ao de bovino. Rebanhos bubalinos para produção de carne e leite apresentam índices zootécnicos superiores àqueles normalmente encontrados em rebanhos bovinos com objetivo semelhante.

Características zootécnicas como docilidade, rusticidade, prolificidade, adaptabilidade, precocidade e longevidade aliadas à grande capacidade de adaptabilidade, tornam o búfalo uma boa alternativa de produção de carne e leite para a população. Tudo isso aliado às taxas de natalidade superior a $80 \%$ e de mortalidade inferior a $3 \%$ ao ano.

\section{BÚFALOS}

Os búfalos foram domesticados no terceiro milênio a.C., na Mesopotâmia, e no segundo milênio a.C., na China. Durante a Idade Média, os búfalos foram introduzidos na Europa, extremo Oriente e África. No Brasil, eles chegaram entre 1870 e 1890, através da Ilha de Marajó, no estado do Pará, trazidos por fugitivos procedentes da Guiana Francesa, e devido a grande capacidade de adaptação aos mais diversos climas, multiplicaram-se rapidamente (Rocha ${ }^{2}$, 2007; Zava, 1987).

No Brasil, estes animais têm uma história bem curta, ao se comparar com o tempo de exploração bovina em nosso país, que data da chegada dos colonizadores portugueses, há 500 anos. As primeiras criações de búfalos surgiram com a chegada dos primeiros animais ao Brasil, há cerca de um século (Rocha ${ }^{1}$, 2007). Das várias raças existentes no mundo, o Brasil possui quatro (Murrah, Mediterrâneo, Jafarabadi e Carabao) que são reconhecidas pela Associação Brasileira de Criadores de Búfalos (Rocha² ${ }^{2}$ 2007).

A criação de búfalos, no Brasil, é favorecida e pode ser viabilizada mais facilmente em áreas nas quais a criação de bovinos seria mais difícil, como 
VIEIRA, J.N., et al. Bubalinocultura no Brasil: Short communication. PUBVET, Londrina, V. 5, N. 2, Ed. 149, Art. 1003, 2011.

regiões alagadas a exemplo do que acontece nas famosas criações da Ilha de Marajó, reduto inicial deste tipo de criação no nosso país. Além disso, é conhecida a grande capacidade dos búfalos engordarem com forragens grosseiras e converter pastagens nativas em ótimo ganho de peso. Isso é muito útil em um país com as características como as do Brasil, no qual encontramos gigantescas áreas de pastagens naturais, ideais para a criação de búfalos. (Rocha ${ }^{1}$, 2007). Em função de sua rusticidade, são animais bastante adaptados a solos de baixa fertilidade, terrenos alagadiços, sendo capazes de converter alimentos fibrosos em proteínas de alto valor (carne e leite), apresentando longevidade e possibilidade de ocupar áreas geográficas não adequadas às demais espécies de ruminantes. Nos países latino-americanos, especialmente no Brasil, sua contribuição nesses aspectos tem crescido nos últimos anos, e deverá se tornar de grande importância, não só para as propriedades rurais como também para as empresas produtoras e processadoras de alimentos (Oliveira, 2005; Moreira et al., 1994).

O búfalo é considerado um animal de dupla aptidão, isto é, se mostra adequado tanto para a produção de leite como de carne. Entretanto, devido à sua força e resistência, é utilizado também como animal de tração. Dessa forma é considerado um animal de tripla aptidão, em especial em terrenos pantanosos ou inundados, como acontece em países da Ásia, Índia e no Norte do Brasil (Oliveira, 2005).

Com a crescente tendência de consumo de carnes menos gordurosas, com baixos teores de colesterol e com alto valor protéico, o consumo de carne de búfalo está crescendo substancialmente e tornando esta atividade pecuária cada vez mais atrativa para investidores do setor rural brasileiro, Tabela 01 (Rocha ${ }^{1}$, 2007; Oliveira, 2005). A carne de búfalo é utilizada tanto na venda do produto resfriado ou congelado como, também, na produção de hambúrgueres, salsichas, etc. É uma carne considerada magra, com baixos teores de colesterol e com aspecto e gosto semelhante ao da carne bovina (Rocha ${ }^{1}$, 2007). 
VIEIRA, J.N., et al. Bubalinocultura no Brasil: Short communication. PUBVET, Londrina, V. 5, N. 2, Ed. 149, Art. 1003, 2011.

Tabela 01: Diferenças da composição centesimal, Colesterol e Energia fornecida por cortes e carnes cruas e cozidas de bubalinos e bovinos

\begin{tabular}{ccccc}
\hline Nutriente & $\begin{array}{c}\text { Cortes e Carnes cruas } \\
\text { Bubalino }\end{array}$ & $\begin{array}{c}\text { Cortes e Carnes cozidas } \\
\text { Bovino }\end{array}$ & $\begin{array}{c}\text { Bubalino } \\
\text { Bovino }\end{array}$ \\
\hline Água (\%) & 76,30 & 73,28 & 68,81 & 66,03 \\
Proteína (\%) & 20,39 & 21,41 & 26,83 & 26,29 \\
Lipídios (\%) & 1,37 & 5 & 1,80 & 6,55 \\
Cinzas (\%) & 1,05 & 1,05 & 1,39 & 1,06 \\
Colesterol (mg) & 46 & 62 & 61 & 76 \\
Energia (Kcal) & 99 & 137 & 131 & 171 \\
\hline
\end{tabular}

FONTE: Oliveira (2005) - modificado.

A criação de búfalos no Brasil visa, além da produção de carne, a produção de leite que apresenta maior valor nutritivo, altos níveis de gordura, proteínas e minerais (em especial o cálcio) quando comparado ao leite de vaca. O Leite é consumido in natura ou no mercado de derivados. A mozzarella de leite de búfala, representa $70 \%$ de comercialização dentre os derivados produzidos. Porém, nos últimos anos, uma série de derivados entrou no mercado, como o doce de leite e a manteiga. Desta forma, a criação de búfalos ou bubalinocultura tornou-se uma alternativa viável e altamente rentável para pecuaristas de todo o Brasil (Rocha ${ }^{1}$, 2007; Revista Rural, 2008).

Devido a todas estas qualidades, tanto a Argentina como a Colômbia estão interessados em importar animais do Brasil para focar na produção de leite. Já a Venezuela pretende criar o animal voltado para a cultura de carne. Já para o Oriente Médio, o Brasil exporta animais em pé para o abate visando à produção de carne, a cerca de dois anos. Este tipo de comércio está sendo realizado inicialmente com o Líbano (Revista Rural, 2008)

O rebanho nacional vem crescendo de maneira constante e significativa e, o que é mais representativo, em todas as regiões do País, o que derrubou o estigma de que a criação deste animal só era possível na região Norte do Brasil na qual, de fato, possui o maior rebanho (Rocha ${ }^{1}$, 2007; IBGE, 2008).

\section{DEMOGRAFIA DE BÚFALOS}


VIEIRA, J.N., et al. Bubalinocultura no Brasil: Short communication. PUBVET, Londrina, V. 5, N. 2, Ed. 149, Art. 1003, 2011.

De acordo com os dados do Instituto Brasileiro de Geografia e Estatística (IBGE, 2007), o efetivo de bubalinos em 31.12.2007, foi de 1.131 .986 cabeças. A Tabela 01 mostra a distribuição do rebanho no Brasil.

Tabela 01: Efetivo do rebanho bubalino, nas cinco regiões do Brasil, em 31.12.2007

\begin{tabular}{ccc}
\hline Região & No Cabeças & Porcentagem (\%) \\
\hline Norte & 704.424 & 62,3 \\
Sul & 127.966 & 11,3 \\
Nordeste & 119.978 & 10,6 \\
Sudeste & 110.769 & 9,8 \\
Centro-Oeste & 68.849 & 6,0 \\
\hline TOTAL & $\mathbf{1 . 1 3 1 . 9 8 6}$ & $\mathbf{1 0 0}$
\end{tabular}

FONTE: IBGE (2008) - adaptado.

Os dados aqui demonstrados apresentam que o quadro nacional da bubalinocultura tende a mudar a médio e longo prazo afirmando, assim, que o búfalo é um animal com tendência de crescimento da produção e procura de carne, leite e derivados, da produtividade do rebanho nacional. Dessa forma, há a necessidade de maiores estudos nesta espécie, nas mais diversas áreas, como na biotecnologia da reprodução, doenças patológicas e hereditárias, identidade genética e controle qualidade de carne, leite e derivados. Determinando, assim, um registro apropriado do rebanho nacional, uma vez que o Brasil detém o maior rebanho da espécie do Ocidente.

\section{REFERÊNCIAS BIBLIOGRÁFICAS}

IBGE, 2008 - Produção da Pecuária Municipal. 2007. V.35, p.62

MOREIRA, P.; COSTA, A.L.; VALENTIN, J.F. Comportamento produtivo e reprodutivo de bubalinos mestiços Murrah-Mediterrâneo em pastagem cultivada em terra firme, no Estado do Acre. Rio Branco: Embrapa-CPAF-Acre, 1994, 19p. (Boletim de Pesquisa, 13).

OLIVEIRA, AFONSO DE LIGUORI. Búfalos: produção, qualidade de carcaça e de carne. Alguns aspectos quantitativos, qualitativos e nutricionais para promoção do melhoramento genético [Water buffalo: production, carcass and meat quality. Some quantitative, qualitative and nutritional aspects to promote the genetic improvement]. Rev. Bras. Reprod. Anim., Belo Horizonte, v.29, n.2, p.122-134, abril/jun. 2005. Disponível em www.cbra.org.br.

ROCHA, DÉLCIO ${ }^{1}$. Bubalinocultura: Os Búfalos no Brasil. Publicado em 17/05/2007. Disponível em http://www.zootecniabrasil.com.br/, acessado em 01/06/2009. Fonte: Redação Rural News.

ROCHA, DÉLCIO². Bubalinocultura: Búfalo: sinônimo de produção de carne. Publicado em 17/05/2007. Fonte: Embrapa Rondônia. Disponível em http://www.zootecniabrasil.com.br/, acessado em 01/06/2009. 
VIEIRA, J.N., et al. Bubalinocultura no Brasil: Short communication. PUBVET, Londrina, V. 5, N. 2, Ed. 149, Art. 1003, 2011.

ZAVA, M.AR.A. Produção de Búfalos. São Paulo: Instituto Campineiro de Ensino Agrícola, 1987. BÚFALO - SELVAGEM, MAS NEM TANTO! Revista Rural, no 126 - ago./2008, http://www.revistarural.com.br/edicoes/2008/Artigos/rev126 bufalo.htm, acessado em 01/06/2009. 